\title{
Exhaled nitric oxide in patients with chronic obstructive pulmonary disease: a systematic review and meta-analysis
}

REVIEW

This article was published in the following Dove Press journal: International Journal of COPD

\author{
Zhiyu Lu ${ }^{1,2}$ \\ Weina Huang' \\ Linfeng Wang' \\ Ning $X u^{\prime}$ \\ Qunli Ding ${ }^{3}$ \\ Chao Cao' \\ 'Department of Respiratory Medicine, \\ Ningbo First Hospital, Ningbo, \\ People's Republic of China; ${ }^{2}$ Ningbo \\ University School of Medicine, \\ Ningbo, People's Republic of China; \\ ${ }^{3}$ Department of Respiratory Medicine, \\ The Affiliated Hospital of Medical \\ School of Ningbo University, Ningbo, \\ People's Republic of China
}

Correspondence: Chao Cao Department of Respiratory Medicine, Ningbo First Hospital, 59 Liuting Road, Ningbo, Zhejiang 315010, People's Republic of China

Tel/fax +86 57487089878

Email caocdoctor@163.com

Qunli Ding

Department of Respiratory Medicine, The Affiliated Hospital of Medical School of Ningbo University, 247 Renmin Road, Ningbo, Zhejiang 315020, People's Republic of China

Tel/fax +865748703 5778

Email ccding2005@।63.com
Background: Fractional exhaled nitric oxide (FENO) is a useful and noninvasive biomarker for eosinophilic airway inflammation, particularly in asthma. However, its utility in chronic obstructive pulmonary disease (COPD) remains controversial. In this study, we performed a systematic review and meta-analysis to evaluate FENO levels in COPD.

Methods: A search of PubMed, Embase, Cochrane Library, and clinical trial registry was conducted from inception to January 2018. Studies were included if they reported FENO levels in patients with COPD and healthy controls. We then extracted relevant information and analyzed data. Standard mean difference (SMD) with $95 \%$ confidence interval (CI) was applied in this meta-analysis.

Results: A total of 2,073 studies were reviewed for eligibility, with 24 studies pooled for analysis. The FENO levels in patients with COPD were elevated mildly compared with healthy controls (SMD 1.28, 95\% CI 0.60-1.96). A similar result was also observed in stable COPD, with an SMD of 1.21 (95\% CI 0.47-1.96). On the other hand, we found no association between FENO levels and exacerbated COPD. Additionally, for patients with COPD, ex-smokers had higher levels of FENO than current smokers (SMD 2.05, 95\% CI 1.13-2.97).

Conclusion: Our studies demonstrated a mild elevation of FENO in COPD, and the association between exacerbated COPD and FENO levels needs to be further explored. The potential mechanism is still unknown and conflicting.

Keywords: biomarker, chronic obstructive pulmonary disease, fractional exhaled nitric oxide, meta-analysis

\section{Introduction}

Chronic obstructive pulmonary disease (COPD) is currently the fourth leading cause of death; the prevalence of COPD is rapidly increasing, and it is expected to be the third most fatal disease in the world by $2030 .{ }^{1}$ This disease affects approximately 65 million people in the world, of which 90\% deaths occurred in low- and middleincome countries. ${ }^{2}$ COPD is a disease state characterized by progressive and partially reversible airflow obstruction. It is usually accompanied by mucus hypersecretion, inflammation, and oxidation stress in airway and lung. ${ }^{3}$ Later, it can induce symptoms such as dyspnea, nutritional depletion, and diseases such as pulmonary heart disease, diabetes, and depression, all of which cause great impact on the quality of life and health of patients. ${ }^{4,5}$ Since COPD results in great financial and health burdens, it is important to make early, appropriate diagnosis and take steps for the treatment of COPD.

Fractional exhaled nitric oxide (FENO), a biomarker synthesized endogenously in the human respiratory tract, plays a key role in physiological regulation of airway 
function, including neurotransmission, vasodilation, and immunoregulation. ${ }^{6}$ Moreover, FENO is implicated in the pathophysiology of airway disease, and elevated FENO level is found in inflammatory lung disorders such as asthma, pulmonary hypertension, and cystic fibrosis. ${ }^{7}$ The measurement of FENO has been suggested as a simple and noninvasive test in eosinophilic airway inflammation, and the utility in aiding diagnosis and monitoring of asthma has also been confirmed. ${ }^{7,8}$ However, limited by the inconsistent results of FENO level in COPD, the value and application in this case still remains unknown. Interestingly, it was reported that FENO levels in patients with COPD could be reduced by smoking and inhaled corticosteroids, which indicated they were confounding factors in measuring FENO levels in COPD. COPD involves excessive inflammation in airway and lung, which induces the release of numerous proinflammatory cytokines. Yet, the available studies regarding FENO levels are controversial and conflicting in their conclusions. To address this issue, we performed a systematic review and meta-analysis of published studies to determine the levels of FENO in COPD, aiming to further the understanding of the role of FENO in patients with COPD.

\section{Methods}

\section{Search strategy}

A systematic search of PubMed, Embase, and Cochrane Library was conducted up to January 2018. We searched for the terms ("chronic obstructive pulmonary disease" or "COPD") and ("fractional exhaled nitric oxide" or "exhaled nitric oxide" or "nitric oxide" or "FENO"). The search was limited to articles published in the English language and conducted in humans. To ensure that all relevant studies were included, we screened bibliographies of relevant review articles and searched the clinical trial registry (www. ClinicalTrials.gov) for additional studies. Case reports, reviews, editorials, comments, practice guidelines, historical articles, and news were excluded.

\section{Study selection}

Two reviewers (ZL and CC) screened titles and abstracts independently to identify potential relevant citations. Then, the full texts were retrieved and reviewed to confirm eligibility. Differences between the reviewers were resolved by discussion and, if necessary, in consultation with a senior investigator (QD). Studies were included if they met the following criteria: 1) Studies reported FENO levels in both patient group and control group quantitatively. 2) FENO levels were expressed as mean \pm standard deviation, median and range, or median and interquartile range. 3) Patients with COPD and controls had no history of asthma or other respiratory disease.

\section{Data extraction and quality assessment}

The extracted information included study source (surname of first author and year of publication), study design, study population, gender, sample size, diagnostic standard of COPD, FENO measurement, and FENO levels (in parts per billion or ppb) in patients with COPD and in controls. We derived FENO levels expressed as mean \pm standard deviation preferentially. If not available, the median and range, or median and interquartile range were extracted. If multiple flow rates were applied in FENO, we then derived the data at $50 \mathrm{~mL} / \mathrm{s}$ flow rate. Quality assessment of crosssectional studies was conducted by using an 11-item checklist recommended by Agency for Healthcare Research and Quality. Article quality was assessed as follows: low quality ranged from 0 to 3, moderate quality ranged from 4 to 7 , and high quality ranged from 8 to 11 . As for case-control studies, we applied the Newcastle-Ottawa Quality Assessment Scale, with a total score of 0-3, 4-6, and 7-9 considered low, moderate, and high quality, respectively. The quality of all studies was evaluated by a consensus meeting with all authors. Low-quality studies were excluded from our meta-analysis.

\section{Data analysis}

The means and standard deviation were pooled and calculated between patients with COPD and controls. For studies reporting median and range, or median and interquartile range, we analyzed means and standard deviation based on the method proposed by Hozo et al. ${ }^{9}$ For studies reporting FENO levels in stable and exacerbated COPD, both levels were calculated. If there were 2 or more control groups in the included studies, we chose the best match for each group (ex-smokers group and current smokers group). Furthermore, we performed subgroup analyses regarding COPD status including stable and exacerbated COPD, as well as smoking status (ex-smokers and current smokers) in patients with COPD. According to the included studies, stable status was free from no exacerbation of symptom (increased breathlessness, increased cough, and increased sputum production) before research. Exacerbated COPD was defined as acute exacerbation, with a symptom of increased breathlessness, increased cough, and increased sputum production. Heterogeneity was assessed by the $I^{2}$ statistics, with a value of $25 \%-49 \%$ representing low heterogeneity, 50\%-75\% 
moderate heterogeneity, and $>75 \%$ high heterogeneity. Considering the high heterogeneity, a random-effects model was applied to combine the overall effect. In addition, 2 reviewers (ZL and CC) independently used the funnel plot to check the publication bias, and Egger's test was done to access the asymmetry of funnel plots. A 2-sided $P$-value $<0.05$ was judged to indicate statistical significance. Differences between the reviewers were resolved by discussion and, if necessary, in consultation with a senior investigator (QD). We also performed a sensitivity analysis to explore the stability of the meta-analysis. All statistical analyses were conducted with Review Manager version 5.3 (The Cochrane Collaboration, London, UK) and Stata version 13 (StataCorp LLC, College Station, TX, USA).

\section{Results Study selection}

Figure 1 shows details of literature and study selection. Initially, we identified 2,073 records in the electronic databases. After removing duplicates, 1,466 records were left for title and abstract screening. Then, 1,426 citations were discarded, as they were not related to the topic. The remaining 40 studies were retrieved for full-text evaluation. No available data was provided in 4 studies. Nine studies were not related to our study. Two studies reported that patients with

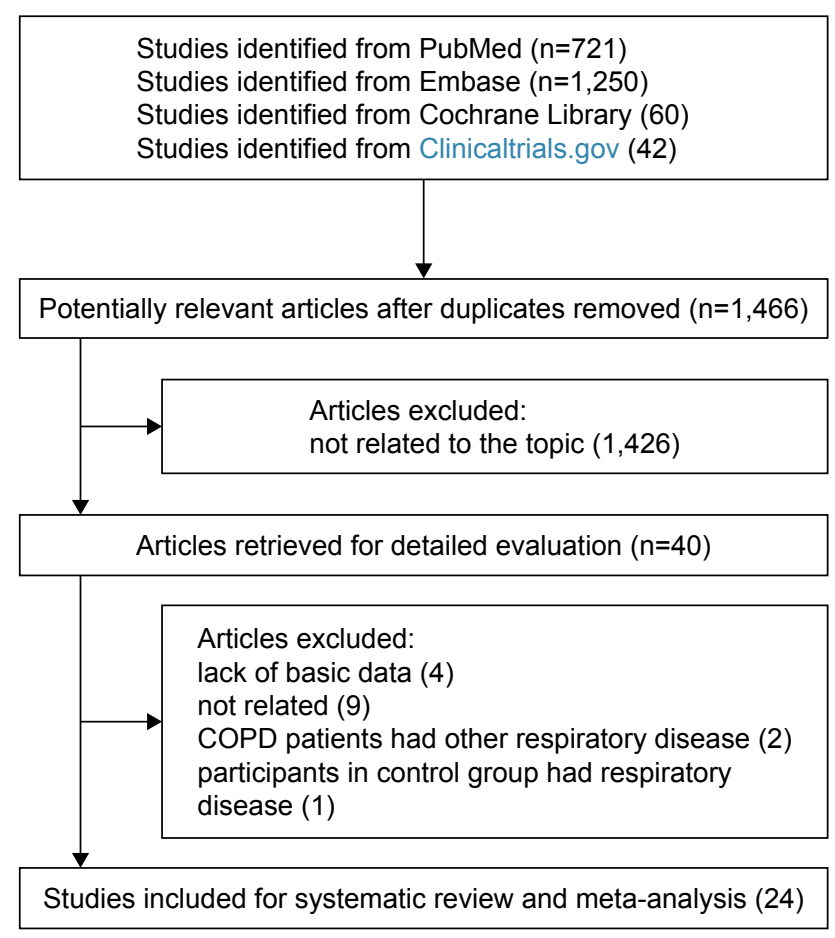

Figure I Flow diagram of literature search and study selection. Abbreviation: COPD, chronic obstructive pulmonary disease.
COPD had other respiratory disease, and 1 study reported that participants in the control group had respiratory disease. Eventually, 24 studies were included in this systematic review and meta-analysis, with 22 cross-sectional studies ${ }^{10-31}$ and 2 case-control studies. ${ }^{32,33}$ As for quality assessment, all the cross-sectional studies had a relatively moderate quality while the case-control studies (Agency for Healthcare Research and Quality score ranged from 4 to 7) had a relatively high quality (Newcastle-Ottawa Quality Assessment Scale score $>7$ ).

Detailed characteristics of included studies are provided in Table 1. The sample size across studies varied from 21 to 212 , with a total number of 1,669 . The majority of studies were from Europe, ${ }^{10-12,15,18-20,22,23,26-30,33}$ with 1 study from Australia, ${ }^{17} 1$ study from America, ${ }^{13} 2$ studies from Africa, ${ }^{21,32}$ and 5 studies from Asia. ${ }^{14,16,24,25,31}$ In terms of diagnosis of COPD, 9 studies used doctor-diagnosis, ${ }^{13,15,17,21,23,29,31,32}$ 8 studies used GOLD guideline, ${ }^{10,12,14,18,22,24,26,30,33} 2$ applied American Thoracic Society criteria, ${ }^{11,16} 2$ applied European Respiratory Society criteria, ${ }^{20,27} 2$ applied British Thoracic Society guidelines, ${ }^{19,28}$ and 1 applied Chinese Medical Association guidelines. $^{25}$

\section{FENO in patients with COPD}

A total of 24 studies evaluated FENO levels in patients with COPD and controls. Due to the evidence of great heterogeneity $\left(I^{2}=96 \%\right)$, a random-effect model was used in this meta-analysis. The pooled standard mean difference (SMD) was 1.28 (95\% confidence interval [CI] 0.60-1.96), which indicated FENO levels were slightly elevated in patients with COPD compared with controls (Figure 2 and Table 2).

\section{Subgroup analyses}

Based on COPD status (stable or exacerbated), we conducted subgroup analyses to evaluate the association between COPD status and FENO levels. Twenty studies were included in the subgroup of stable COPD, contributing 1,393 participants for this meta-analysis. The calculated SMD was 1.21 (95\% CI 0.47-1.96), which meant FENO levels were 1.21 (95\% CI 0.47-1.96) higher than those in the control group (Figure 3 and Table 2). As for subgroup of exacerbated COPD, 2 studies were enrolled and 53 participants were included. The calculated SMD (3.20, 95\% CI -3.22 to 9.61) indicated that there was no association between exacerbated COPD and FENO levels in our meta-analysis (Figure 3 and Table 2).

Considering the smoking status in patients with COPD, we performed another subgroup analysis to compare FENO levels between ex-smokers and current smokers in COPD. 
Table I Characters of included studies

\begin{tabular}{|c|c|c|c|c|c|c|}
\hline Study source & $\begin{array}{l}\text { Study } \\
\text { design }\end{array}$ & $\begin{array}{l}\text { Study } \\
\text { population }\end{array}$ & $\begin{array}{l}\text { Gender } \\
(\mathrm{m} / \mathrm{f})\end{array}$ & $\begin{array}{l}\text { Number of } \\
\text { participants }\end{array}$ & $\begin{array}{l}\text { COPD } \\
\text { diagnosis }\end{array}$ & FENO measurement \\
\hline $\begin{array}{l}\text { Kanazawa } \\
\text { et al, }{ }^{16} 1998\end{array}$ & CS & Japan & $21 / 0$ & 21 & ATS & $\begin{array}{l}\text { Chemiluminescence analyzer (CLM-500; } \\
\text { Shimazu; Kyoto, Japan) }\end{array}$ \\
\hline $\begin{array}{l}\text { Rutgers et al, }{ }^{23} \\
1998\end{array}$ & CS & the Netherlands & $25 / 7$ & 32 & Doctor-diagnosis & $\begin{array}{l}\text { Chemiluminescence analyzer (CLD } 700 \text { AL, } \\
\text { ECO physics, Dürnten, Switzerland) }\end{array}$ \\
\hline $\begin{array}{l}\text { Agusti et al, }{ }^{29} \\
1999\end{array}$ & CS & Spain & $27 / 0$ & 27 & Doctor-diagnosis & $\begin{array}{l}\text { Chemiluminescence analyzer (Dasibi } \\
\text { Environmental, Glendale, CA, USA) }\end{array}$ \\
\hline $\begin{array}{l}\text { Corradi et al, }{ }^{28} \\
1999\end{array}$ & CS & Italy & $32 / 18$ & 50 & BTS & $\begin{array}{l}\text { Chemiluminescence NO analyzer (model } \\
42 \mathrm{~S} ; \text { Thermo Environmental Instruments } \\
\text { Inc, Franklin, MA, USA) }\end{array}$ \\
\hline $\begin{array}{l}\text { Clini et al," } \\
2000\end{array}$ & CS & Italy & $17 / 2$ & 19 & ATS & $\begin{array}{l}\text { Chemiluminescence analyzer (LR } 2000 \\
\text { series; Logan Research; Kent, UK) }\end{array}$ \\
\hline $\begin{array}{l}\text { Delen et al, }{ }^{13} \\
2000\end{array}$ & $\mathrm{CS}$ & America & NA & 77 & Doctor-diagnosis & $\begin{array}{l}\text { Chemiluminescence (model 280; Sievers } \\
\text { Instruments; Boulder, CO, USA) }\end{array}$ \\
\hline $\begin{array}{l}\text { Papi et al, }{ }^{20} \\
2000\end{array}$ & CS & Italy & $24 / 5$ & 29 & ERS & $\begin{array}{l}\text { Chemiluminescence analyzer (NOA 280; } \\
\text { Sievers) }\end{array}$ \\
\hline $\begin{array}{l}\text { Montuschi } \\
\text { et al, }{ }^{19} 200 \mathrm{I}\end{array}$ & $\mathrm{CS}$ & United Kingdom & $27 / 25$ & 52 & BTS & $\begin{array}{l}\text { Chemiluminescence analyzer (model } \\
\text { LR 2000; Logan Research; Rochester, UK) }\end{array}$ \\
\hline $\begin{array}{l}\text { Hogman et al, }{ }^{15} \\
2002\end{array}$ & CS & Sweden & NA & 60 & Doctor-diagnosis & 280 chemiluminescence analyzer (Sievers) \\
\hline $\begin{array}{l}\text { Zietkowski } \\
\text { et al, }{ }^{27} 2005\end{array}$ & CS & Poland & $58 / 29$ & 87 & ERS & $\begin{array}{l}\text { Chemiluminescence technique (Sievers } 280 \mathrm{i} \\
\text { NO analyzer, Sievers) }\end{array}$ \\
\hline $\begin{array}{l}\text { Brindicci et al, } \\
2005\end{array}$ & CS & United Kingdom & $27 / 24$ & 51 & GOLD & $\begin{array}{l}\text { Chemiluminescence analyzer (NIOXH; } \\
\text { Aerocrine AB, Stockholm, Sweden) }\end{array}$ \\
\hline $\begin{array}{l}\text { Ziora et al, }{ }^{26} \\
2007\end{array}$ & CS & Poland & $51 / 12$ & 63 & GOLD & $\begin{array}{l}\text { Chemiluminescent NO analyzer (model } \\
280 \text {, Sievers Instruments) }\end{array}$ \\
\hline Liu et al, ${ }^{17} 2007$ & $\mathrm{CS}$ & Australia & NA & 176 & Doctor-diagnosis & $\begin{array}{l}\text { Chemiluminescent NO analyzer (Dasibi } \\
\text { Environmental Corp.) }\end{array}$ \\
\hline $\begin{array}{l}\text { de Laurentiis } \\
\text { et al, }{ }^{12} 2008\end{array}$ & CS & Italy & NA & 69 & GOLD & $\begin{array}{l}\text { Electrochemical FENO device (NIOX } \\
\text { MINO, Aerocrine)/chemiluminescence } \\
\text { analyzer (NOA, Sensormedics, Milano, Italy) }\end{array}$ \\
\hline Beg et $\mathrm{al}^{3{ }^{31}} 2009$ & $\mathrm{CS}$ & Saudi Arabia & $39 / 0$ & 39 & Doctor-diagnosis & $\begin{array}{l}\text { Chemiluminescence analyzer (SERES, } \\
\text { Aix-en-Provence, France) }\end{array}$ \\
\hline $\begin{array}{l}\text { Lehouck et al, }{ }^{33} \\
2010\end{array}$ & $\mathrm{CC}$ & Belgium & $121 / 30$ & 151 & GOLD & $\begin{array}{l}\text { Chemiluminescence analyzer (NIOX, Flex; } \\
\text { Aerocrine } A B \text { ) }\end{array}$ \\
\hline $\begin{array}{l}\text { Rouhos et al, } \\
2011\end{array}$ & CS & Finland & $|8 / 2|$ & 39 & Doctor-diagnosis & $\begin{array}{l}\text { Chemiluminescence analyzer (Sievers 270B, } \\
\text { Sievers) }\end{array}$ \\
\hline $\begin{array}{l}\text { Maricic et al, }{ }^{18} \\
2013\end{array}$ & CS & Croatia & NA & 100 & GOLD & NA \\
\hline Sun et al,,$^{25} 2013$ & $\mathrm{CS}$ & $\begin{array}{l}\text { People's Republic } \\
\text { of China }\end{array}$ & $35 / 10$ & 45 & CMA & $\begin{array}{l}\text { The 4540- I999b portable nitric oxide gas } \\
\text { detector (Interscan Corporation, Simi } \\
\text { Valley, CA USA) }\end{array}$ \\
\hline $\begin{array}{l}\text { Hirano et al, }{ }^{14} \\
2013\end{array}$ & $\mathrm{CS}$ & Japan & $24 / 12$ & 36 & GOLD & $\begin{array}{l}\text { Chemiluminescence-based NO analyzer } \\
\text { NA-623N, (Chest Co. and Kimoto Electric } \\
\text { Co., Tokyo, Japan) }\end{array}$ \\
\hline $\begin{array}{l}\text { Moussa et al, } \\
2014\end{array}$ & $\mathrm{CC}$ & Tunisia & $45 / 0$ & 45 & Doctor-diagnosis & $\begin{array}{l}\text { Electrochemical analyzer (Medisoft, Dinant, } \\
\text { Belgium) }\end{array}$ \\
\hline $\begin{array}{l}\text { Rawy and } \\
\text { Mansour, } 2015\end{array}$ & CS & Egypt & $61 / 29$ & 90 & Doctor-diagnosis & Niox Mino analyzer (Aerocrine AG) \\
\hline $\begin{array}{l}\text { Santini et al, } \\
2016\end{array}$ & CS & Italy & $67 / 22$ & 99 & GOLD & NIOX system (Aerocrine) \\
\hline $\begin{array}{l}\text { Shrestha et al, }{ }^{24} \\
2017\end{array}$ & CS & Nepal & $91 / 121$ & 212 & GOLD & $\begin{array}{l}\text { Handheld Bedfont NO breath point-of-care } \\
\text { device (Bedfont Scientific Ltd, Maidstone, } \\
\text { Kent, UK, registered in England and Wales) }\end{array}$ \\
\hline
\end{tabular}

Abbreviations: ATS, American Thoracic Society criteria; BTS, British Thoracic Society guidelines; CC, case-control study; CMA, Chinese Medical Association guidelines; COPD, chronic obstructive pulmonary disease; CS, cross-sectional study; ERS, European Respiratory Society criteria; FENO, fractional exhaled nitric oxide; GOLD, Global Initiative for Obstructive Lung Disease; NA, not available. 


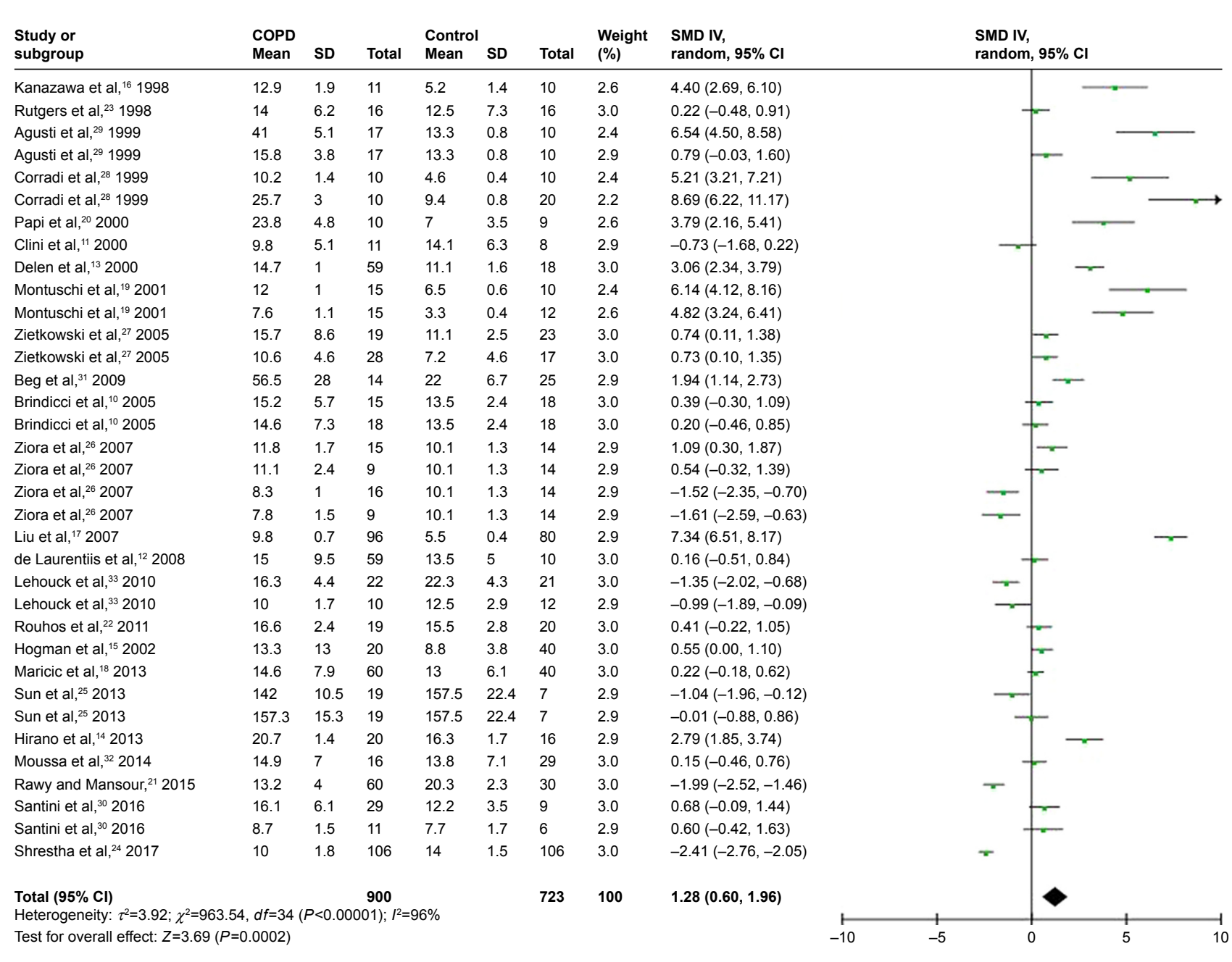

Figure 2 Comparison of FENO levels between COPD patients and controls in the included studies.

Abbreviations: $\mathrm{Cl}$, confidence interval; COPD, chronic obstructive pulmonary disease; FENO, fractional exhaled nitric oxide; IV, inverse variance; SMD, standard mean deviation; SD, standard deviation.

A random-effect model was used because of the high heterogeneity $\left(I^{2}=90 \%\right)$. The result revealed that FENO levels in ex-smokers were higher than those in current smokers, with a pooled SMD of 2.05 (95\% CI 1.13-2.97) (Figure 4 and Table 2).

\section{Sensitivity analysis and publication bias}

We sequentially extracted each study and performed a sensitivity analysis. We found that the SMDs were not materially altered, which showed the stability of this meta-analysis (Figure S1). The funnel plot demonstrated asymmetry,

Table 2 Subgroup analyses

\begin{tabular}{|c|c|c|c|c|}
\hline & Studies (n) & Participants & SMD (95\% CI) & $I^{2}(\%)$ \\
\hline Total & 24 & 1,669 & $1.28(0.60-1.96)$ & 96 \\
\hline \multicolumn{5}{|l|}{ Subgroup } \\
\hline \multicolumn{5}{|l|}{ COPD status } \\
\hline Stable & 20 & $\mathrm{I}, 393$ & I.2I (0.47-I.96) & 96 \\
\hline Exacerbated & 2 & 53 & $3.20(-3.22$ to 9.61$)$ & 97 \\
\hline \multicolumn{5}{|c|}{ Smoking status in COPD } \\
\hline \multicolumn{5}{|c|}{ ex-smokers/current smokers } \\
\hline COPD & 7 & 323 & $2.05(1.13-2.97)$ & 90 \\
\hline
\end{tabular}

Abbreviations: $\mathrm{Cl}$, confidence interval; COPD, chronic obstructive pulmonary disease; SMD, standard mean difference. 


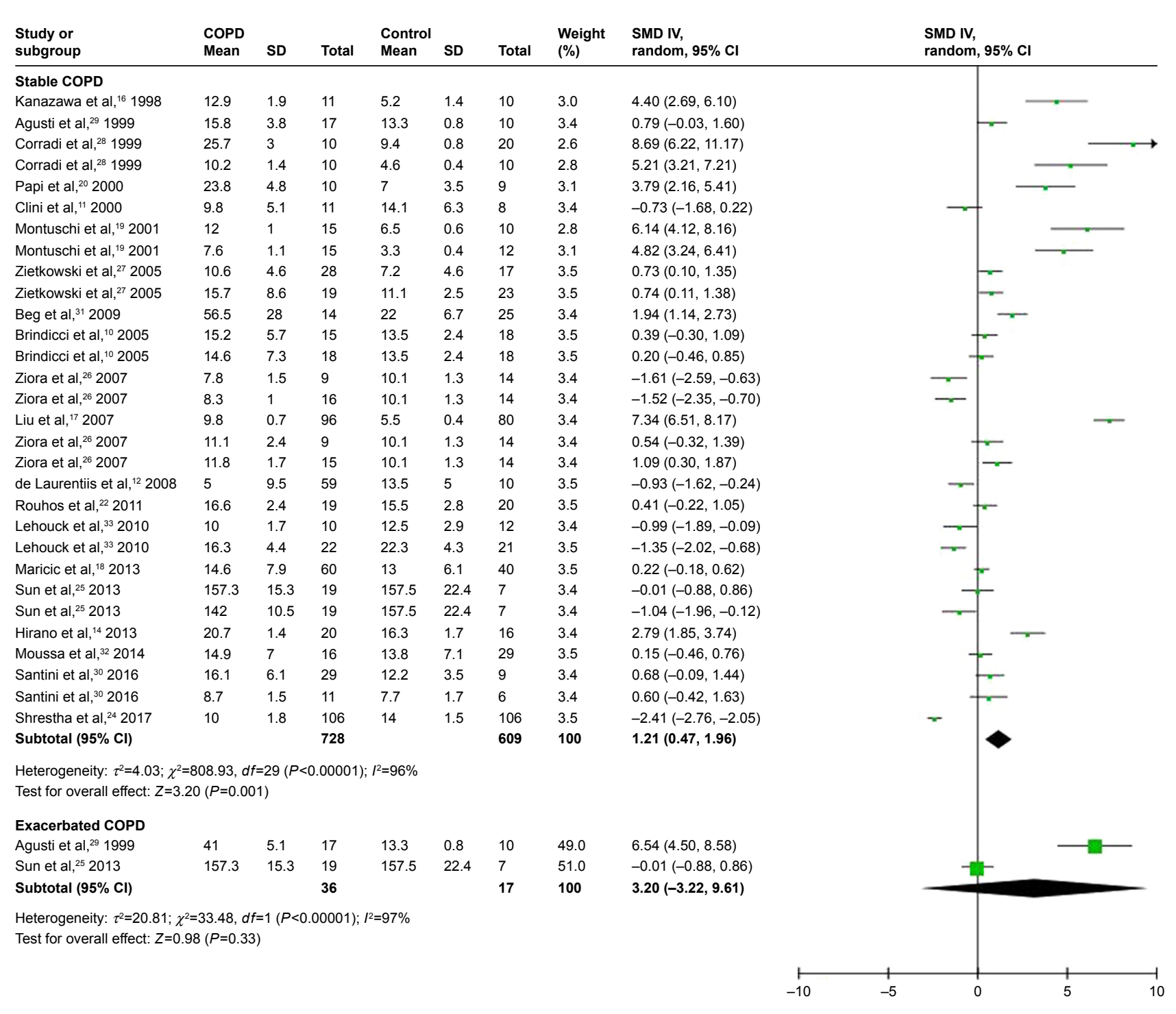

Figure 3 Comparison of fractional exhaled nitric oxide levels between stable/exacerbated COPD patients and controls.

Abbreviations: $\mathrm{Cl}$, confidence interval; COPD, chronic obstructive pulmonary disease; FENO, fractional exhaled nitric oxide; IV, inverse variance; SMD, standard mean deviation; SD, standard deviation.

indicating an obvious bias. Further (Figure S2), the Egger's tests also suggested the presence of publication bias among the included studies $(P<0.001)$.

\section{Discussion}

To our knowledge, this is the first meta-analysis assessing FENO levels in patients with COPD. Twenty-four studies and 1,393 participants were included in the systematic review and meta-analysis. The results showed elevated FENO levels in patients with COPD compared with healthy controls. Further, the subgroup analyses, which were based on the disease state of COPD, revealed that patients with stable COPD had a mild elevation of FENO levels. No association was found between FENO levels and exacerbated COPD, which might result from the limited number of studies. And for subjects with COPD, it was found that FENO levels were much higher in ex-smokers than those in current smokers.

Identifying biomarkers for COPD could reflect disease state and underlying pathology. FENO has been a marker for eosinophilic inflammation. Positive correlation between FENO and eosinophilia has been confirmed in induced sputum and bronchoalveolar lavage. ${ }^{34,35}$ Since asthma is a disease characterized by airway inflammation via eosinophilic cellular pathway, FENO measurement has value in aiding in the diagnosis of asthma. However, its role in COPD still remains controversial because of a different type of airway inflammation.

COPD is mainly characterized by overexpression and infiltration of neutrophils, macrophages, and T-lymphocytes. ${ }^{36}$ 


\begin{tabular}{|c|c|c|c|c|c|c|c|}
\hline $\begin{array}{l}\text { Study or } \\
\text { subgroup }\end{array}$ & \multicolumn{2}{|c|}{ Ex-smokers } & Total & \multicolumn{2}{|c|}{ Current smokers } & Total & $\begin{array}{l}\text { Weight } \\
(\%)\end{array}$ \\
\hline Corradi et al, ${ }^{28} 1999$ & 25.7 & 3 & 10 & 10.2 & 1.4 & 10 & 8.3 \\
\hline Montuschi et al, ${ }^{19} 2001$ & 15 & 1 & 15 & 7.6 & 1.1 & 15 & 9.8 \\
\hline Zietkowski et al, ${ }^{27} 2005$ & 15.7 & 8.6 & 19 & 10.6 & 4.6 & 28 & 16.7 \\
\hline Liu et al, ${ }^{17} 2007$ & 10.3 & 1 & 47 & 9.2 & 1.2 & 48 & 17.3 \\
\hline de Laurentiis et al, ${ }^{12} 2008$ & 18.1 & 11 & 47 & 12.6 & 7.3 & 12 & 16.5 \\
\hline Lehouck et al, ${ }^{33} 2010$ & 16.3 & 4.4 & 22 & 10 & 1.7 & 10 & 15.5 \\
\hline Santini et al,$^{30} 2016$ & 16.1 & 6.1 & 29 & 8.7 & 1.5 & 11 & 16.0 \\
\hline \multicolumn{3}{|l|}{ Total $(95 \% \mathrm{Cl})$} & 189 & & & 134 & 100 \\
\hline \multicolumn{8}{|c|}{ Heterogeneity: $\tau^{2}=1.24 ; \chi^{2}=57.19, d f=6(P<0.00001) ; l^{2}=90 \%$} \\
\hline
\end{tabular}

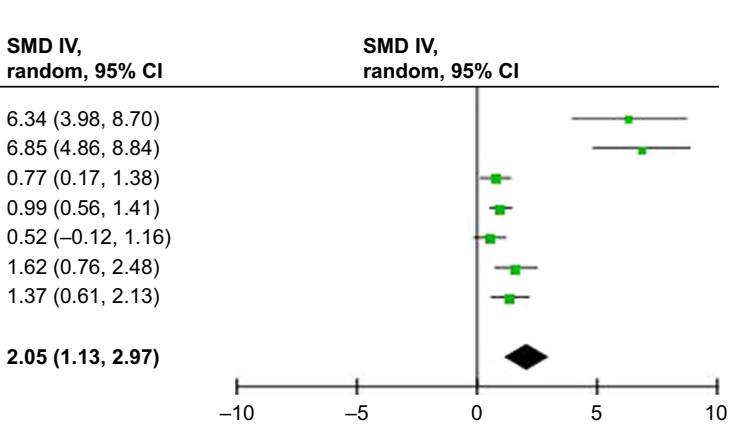

Figure 4 Comparison of FENO levels between ex-smokers and current smokers.

Abbreviations: $\mathrm{Cl}$, confidence interval; FENO, fractional exhaled nitric oxide; IV, inverse variance; SMD, standard mean deviation; SD, standard deviation.

Numerous inflammatory cytokines are then produced and released; such process might include synthesis of iNOS by macrophages, epithelium, and vascular smooth muscle in airway.$^{37}$ In response to stimulants such as viral infections, elevated NO level inversely reflects on the inflammatory process by production of proinflammatory cytokines in the airway and pulmonary system. ${ }^{38}$ On the other hand, evidence showed bacterial infections decreased FENO levels. ${ }^{39}$ Interestingly, the high concentration of $\mathrm{NO}$ in cigarette smoke was believed to reduce FENO, which might result from changes in $\mathrm{NO}$ mechanism. It was reported the high concentration of $\mathrm{NO}$ produced by cigarette smoking downregulated NOS. Besides, another possibly was that oxidants in smoke directly caused damage to bronchial epithelial cells and suppressed production of NO. ${ }^{40,41}$ Since the precise mechanism is not fully understood, we need more research in this field. Agusti et al ${ }^{29}$ found an obvious elevation of FENO levels in exacerbated COPD, and the potential mechanism might be associated with a burst of eosinophilic inflammation and activation of NOS. Pedoto et a ${ }^{42}$ suggested another mechanism: acidosis, which occurred in COPD exacerbation. This acted on the vasculature and resulted in activated myeloperoxidase activity, and eventually increased FENO levels. These findings indicated FENO is a surrogate biomarker and method to detect disease activity in COPD. However, we could not conclude an elevation in exacerbated COPD due to the reduced number of studies included here.

FENO might be a biomarker for corticosteroid treatment. Lim et a ${ }^{43}$ conducted a meta-analysis and concluded that inhaled corticosteroids decreased FENO levels in patients with COPD, especially in ex-smokers with COPD. However, limited by the data, it was not clear whether such changes existed in current smokers with COPD. The observation indicated that airway inflammation in COPD was corticosteroid sensitive, which meant corticosteroids might reflect on NO mechanism, NOS, and NO-producing epithelial cells. Yet, the underlying mechanism remains unknown and requires further research. Interestingly, regardless of use of inhaled corticosteroids, FENO remained at a high concentration during hospitalization and returned to normal values only after several months of inhaled corticosteroids therapy. ${ }^{29}$ This was different from the effect of inhaled corticosteroids in asthma, but consistent with result observed in stable COPD. ${ }^{44}$ Such a difference has also been reported in induced sputum. ${ }^{45}$ Thus, these results supported the concept that the potential inflammatory pathology between asthma and COPD is not the same. In addition, there were some factors increasing FENO levels including nitrate-rich diets and viral infections, as well as factors decreasing FENO levels such as exercise and bronchoconstriction. ${ }^{6}$

\section{Limitations}

Several limitations of our meta-analysis need to be emphasized. First is the relatively small number of participants included. The total number was still not large enough, which may lower the statistical significance. Second, inconsistent measurements of FENO were used. Multiple analyzers and expiratory flow rates were applied, which might be reasons why FENO levels varied widely among the studies. The validity of a meta-analysis mostly depends on the quality of the included studies. However, the ability to detect FENO might vary among institutions in which those studies were performed and might cause bias of the reported NO levels. Considering this limitation, calculation using the randomeffects model might be able to minimize this problem. Inhaled steroid treatment is another vital confounding factor of FENO measurement since inhaled corticosteroids decreased FENO levels and inhaled $\beta_{2}$ agonists increased FENO levels. ${ }^{46}$ However, not all participants included in this meta-analysis were free from such treatment. Limited by the data, we did 
not perform analyses assessing FENO levels in subjects free from inhaled steroid treatment. Additionally, the association between FENO levels and quality of life and pulmonary function were also unevaluable due to the amount of information available. It is necessary to acknowledge another limitation in our search strategy. We did not search the Chinese database. Several studies aiming at the association between COPD and FENO levels in Chinese might have been excluded from this study. Our funnel plot showed an obvious publication bias, which may result from clinical and methodological differences among studies. Another source of asymmetry may be from the studies where the sample size was small but the result showed a strong effect.

\section{Future practice}

The usefulness of FENO measurement in clinical management of COPD still needs to be evaluated in a long term of practice and requires more high-quality studies. Importantly, the association between exacerbated COPD and FENO levels and the underlying mechanism in COPD exacerbation should be further investigated and explained. Since COPD is a neutrophilic airway inflammation, it is interesting that antioxidants and theophylline may have an effect on COPD since they may interfere with neutrophilic inflammation.

\section{Conclusion}

Our findings indicated a mild elevation in FENO levels in patients with COPD compared with controls, as well as in patients with stable COPD. No association was observed in exacerbated COPD, which might result from the limited studies assessed. With regard to difference in smoking status in COPD, we concluded that ex-smokers had higher levels of FENO than current smokers.

\section{Funding}

We acknowledge funding from the program for the National Natural Science Foundation of China (81700025), Medical and Health Science and Technology Project of Zhejiang (2018245859), Beijing Medical Health Foundation (YWJKJJHKYJJ-HX32), and the Medical Science and Technology Plan Projects of Ningbo (2016A03).

\section{Author contribution}

ZL, QD, and CC conceived the study. ZL, WH, and LW selected studies and collected data. ZL and NX conducted the statistical analyses. ZL wrote the first draft, and all authors contributed to the final manuscript. All authors contributed toward data analysis, drafting and critically revising the paper and agree to be accountable for all aspects of the work.

\section{Disclosure}

The authors report no conflicts of interest in this work.

\section{References}

1. Mathers CD, Loncar D. Projections of global mortality and burden of disease from 2002 to 2030. PLoS Med. 2006;3(11):e442.

2. Guo Y, Zhang T, Wang Z, et al. Body mass index and mortality in chronic obstructive pulmonary disease: a dose-response meta-analysis. Medicine. 2016;95(28):e4225.

3. Barnes PJ. Inflammatory mechanisms in patients with chronic obstructive pulmonary disease. J Allergy Clin Immunol. 2016;138(1):16-27.

4. Cazzola M, Calzetta L, Bettoncelli G, et al. Cardiovascular disease in asthma and COPD: a population-based retrospective cross-sectional study. Resp Med. 2012;106(2):249-256.

5. Cazzola M, Bettoncelli G, Sessa E, Cricelli C, Biscione G. Prevalence of comorbidities in patients with chronic obstructive pulmonary disease. Respiration. 2010;80(2):112-119.

6. Stewart L, Katial R. Exhaled nitric oxide. Immunol Allergy Clin North Am. 2007;27(4):571-586.

7. Guo Z, Wang Y, Xing G, Wang X. Diagnostic accuracy of fractional exhaled nitric oxide in asthma: a systematic review and meta-analysis of prospective studies. J Asthma. 2016;53(4):404-412.

8. Saito J, Sato S, Hasunuma H, et al. Off-line fractional exhaled nitric oxide measurement is useful to screen allergic airway inflammation in an adult population. $J$ Asthma. 2007;44(10):805-810.

9. Hozo SP, Djulbegovic B, Hozo I. Estimating the mean and variance from the median, range, and the size of a sample. BMC Med Res Methodol. 2005;5(1):13.

10. Brindicci C, Ito K, Resta O, Pride NB, Barnes PJ, Kharitonov SA. Exhaled nitric oxide from lung periphery is increased in COPD. Eur Respir J. 2005;26(1):52-59.

11. Clini E, Bianchi L, Vitacca M, Porta R, Foglio K, Ambrosino N. Exhaled nitric oxide and exercise in stable COPD patients. Chest. 2000; 117(3):702-707.

12. de Laurentiis G, Maniscalco M, Cianciulli F, et al. Exhaled nitric oxide monitoring in COPD using a portable analyzer. Pulm Pharmacol Ther. 2008;21(4):689-693.

13. Delen FM, Sippel JM, Osborne ML, Law S, Thukkani N, Holden WE. Increased exhaled nitric oxide in chronic bronchitis: comparison with asthma and COPD. Chest. 2000;117(3):695-701.

14. Hirano T, Matsunaga K, Sugiura H, et al. Relationship between alveolar nitric oxide concentration in exhaled air and small airway function in COPD. J Breath Res. 2013;7(4):046002.

15. Hogman M, Holmkvist T, Wegener T, et al. Extended NO analysis applied to patients with COPD, allergic asthma and allergic rhinitis. Respir Med. 2002;96(1):24-30.

16. Kanazawa H, Shoji S, Yoshikawa T, Hirata K, Yoshikawa J. Increased production of endogenous nitric oxide in patients with bronchial asthma and chronic obstructive pulmonary disease. Clin Exp Allergy. 1998;28(10): 1244-1250.

17. Liu J, Sandrini A, Thurston MC, et al. Nitric oxide and exhaled breath nitrite/nitrates in chronic obstructive pulmonary disease patients. Respiration. 2007;74(6):617-623.

18. Maricic L, Vceva A, Visevic R, et al. Assessment of endothelial dysfunction by measuring von Willebrand factor and exhaled nitric oxide in patients with chronic obstructive pulmonary disease. Coll Antropol. 2013; 37(4):1153-1160.

19. Montuschi P, Kharitonov SA, Barnes PJ. Exhaled carbon monoxide and nitric oxide in COPD. Chest. 2001;120(2):496-501. 
20. Papi A, Romagnoli M, Baraldo S, et al. Partial reversibility of airflow limitation and increased exhaled NO and sputum eosinophilia in chronic obstructive pulmonary disease. Am J Respir Crit Care Med. 2000;162(5): 1773-1777.

21. Rawy AM, Mansour AI. Fraction of exhaled nitric oxide measurement as a biomarker in asthma and COPD compared with local and systemic inflammatory markers. Egypt J Chest Dis Tuberc. 2015;64(1):13-20.

22. Rouhos A, Kainu A, Piirila P, et al. Repeatability of exhaled nitric oxide measurements in patients with COPD. Clin Physiol Funct Imaging. 2011;31(1):26-31.

23. Rutgers SR, Meijer RJ, Kerstjens HA, van der Mark TW, Koëter GH, Postma DS. Nitric oxide measured with single-breath and tidal-breathing methods in asthma and COPD. Eur Respir J. 1998;12(4):816-819.

24. Shrestha SK, Shrestha S, Sharma L, Pant S, Neopane A. Comparison of fractional exhaled nitric oxide levels in chronic obstructive pulmonary disease, bronchial asthma and healthy subjects of Nepal. J Breath Res. 2017;11(4):047101.

25. Sun Y, Wang XM, Chen YH, Zhu RX, Liao CC. Exhaled hydrogen sulfide in patients with chronic obstructive pulmonary disease and its correlation with exhaled nitric oxide. Chin Med J (Engl). 2013;126(17): 3240-3244.

26. Ziora D, Dworniczak S, Kaczmarczyk G, Jastrzebski D, Krzywiecki A, Kozielski J. Correlation of exhaled nitric oxide with nitrogen oxides and selected cytokines in induced sputum of chronic obstructive pulmonary disease patients. J Physiol Pharmacol. 2007;58 Suppl 5(Pt 2): 791-799.

27. Zietkowski Z, Kucharewicz I, Bodzenta-Lukaszyk A. The influence of inhaled corticosteroids on exhaled nitric oxide in stable chronic obstructive pulmonary disease. Resp Med. 2005;99(7):816-824.

28. Corradi M, Majori M, Cacciani GC, Consigli GF, de'Munari E, Pesci A Increased exhaled nitric oxide in patients with stable chronic obstructive pulmonary disease. Thorax. 1999;54(7):572-575.

29. Agusti AG, Villaverde JM, Togores B, Bosch M. Serial measurements of exhaled nitric oxide during exacerbations of chronic obstructive pulmonary disease. Eur Respir J. 1999;14(3):523-528.

30. Santini G, Mores N, Shohreh R, et al. Exhaled and non-exhaled non-invasive markers for assessment of respiratory inflammation in patients with stable COPD and healthy smokers. J Breath Res. 2016; 10(1):017102.

31. Beg MF, Alzoghaibi MA, Abba AA, Habib SS. Exhaled nitric oxide in stable chronic obstructive pulmonary disease. Ann Thorac Med. 2009; 4(2):65-70.

32. Moussa SB, Sfaxi I, Tabka Z, Saad HB, Rouatbi S. Oxidative stress and lung function profiles of male smokers free from COPD compared to those with COPD: a case-control study. Libyan J Med. 2014;9(1): 23873 .
33. Lehouck A, Carremans C, De Bent KD, Decramer M, Janssens W. Alveolar and bronchial exhaled nitric oxide in chronic obstructive pulmonary disease. Resp Med. 2010;104(7):1020-1026.

34. Berlyne GS, Parameswaran K, Kamada D, Efthimiadis A, Hargreave FE. A comparison of exhaled nitric oxide and induced sputum as markers of airway inflammation. J Allergy Clin Immunol. 2000;106(4):638-644.

35. Warke T, Fitch P, Brown V, et al. Exhaled nitric oxide correlates with airway eosinophils in childhood asthma. Thorax. 2002;57(5):383-387.

36. Pesci A, Balbi B, Majori M, et al. Inflammatory cells and mediators in bronchial lavage of patients with chronic obstructive pulmonary disease. Eur Respir J. 1998;12(2):380-386.

37. Hogg J, Chu F, Utokaparch S, et al. The nature of small-airway obstruction in chronic obstructive pulmonary disease. $N$ Engl J Med. 2004; 350(26):2645-2653.

38. Carraro S, Andreola B, Alinovi R, et al. Exhaled leukotriene B4 in children with community acquired pneumonia. Pediatr Pulmonol. 2008; 43(10):982-986

39. Papi A, Bellettato CM, Braccioni F, et al. Infections and airway inflammation in chronic obstructive pulmonary disease severe exacerbations. Am J Respir Crit Care Med. 2006;173(10):1114-1121.

40. Hoyt JC, Robbins RA, Habib M, et al. Cigarette smoke decreases inducible nitric oxide synthase in lung epithelial cells. Exp Lung Res. 2003;29(1):17-28.

41. Hutchison SJ, Sievers RE, Zhu BQ, et al. Secondhand tobacco smoke impairs rabbit pulmonary artery endothelium-dependent relaxation. Chest. 2001;120(6):2004-2012.

42. Pedoto A, Caruso JE, Nandi J, et al. Acidosis stimulates nitric oxide production and lung damage in rats. Am J Respir Crit Care Med. 1999; 159(2):397-402.

43. Lim CS, Rani FA, Tan LE. Response of exhaled nitric oxide to inhaled corticosteroids in patients with stable COPD: a systematic review and meta-analysis. Clin Respir J. 2018;12:218-226.

44. Yates DH, Kharitonov SA, Thomas PS, Barnes PJ. Endogenous nitric oxide is decreased in asthmatic patients by an inhibitor of inducible nitric oxide synthase. Am J Respir Crit Care Med. 1996;154(1):247-250.

45. Keatings VM, Barnes PJ. Granulocyte activation markers in induced sputum: comparison between chronic obstructive pulmonary disease, asthma, and normal subjects. Am J Respir Crit Care Med. 1997;155(2): 449-453.

46. Silkoff PE, Wakita S, Chatkin J, et al. Exhaled nitric oxide after $\beta 2$-agonist inhalation and spirometry in asthma. Am J Respir Crit Care Med. 1999;159(3):940-944. 


\section{Supplementary materials}

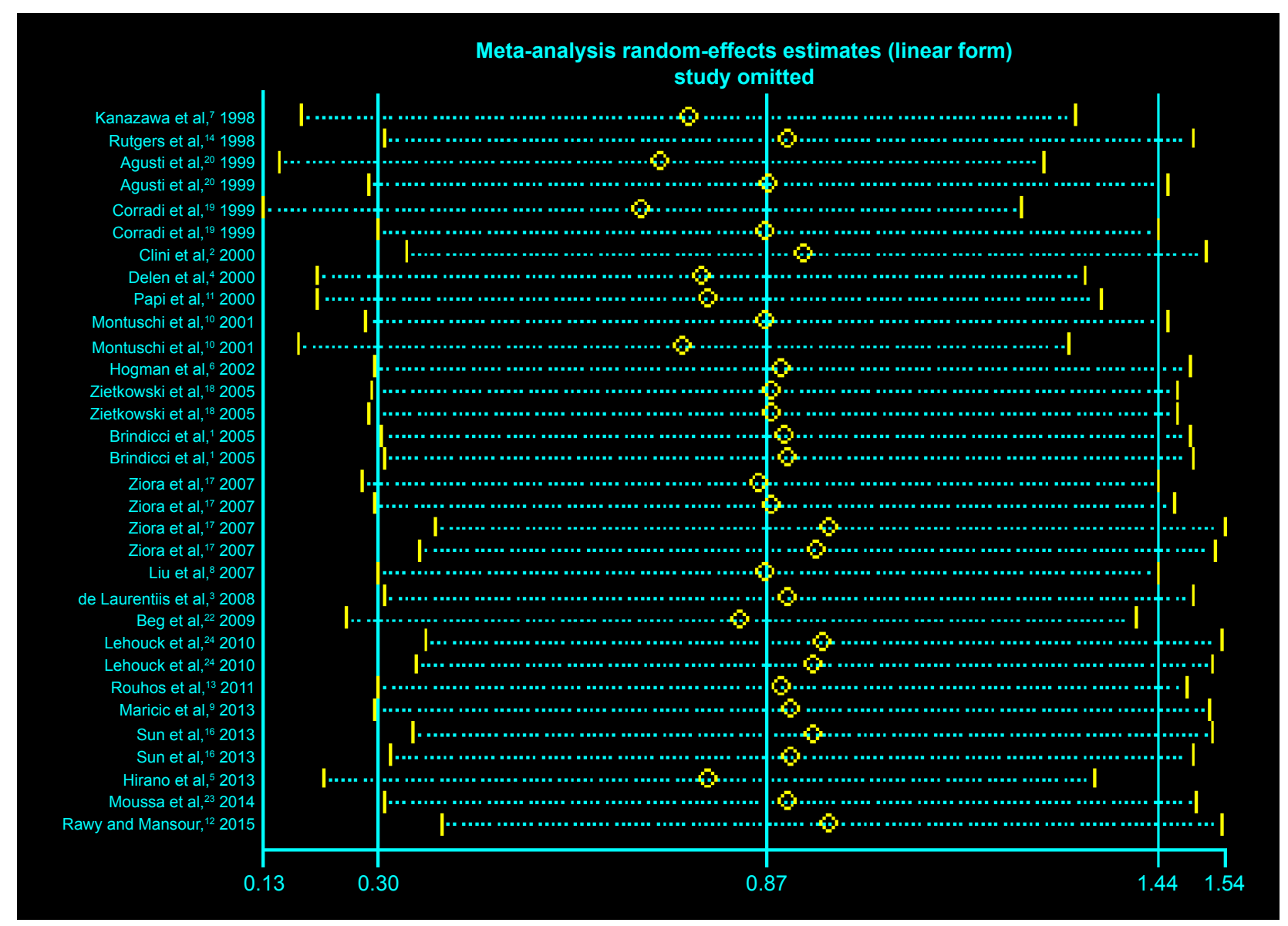

Figure SI Sensitivity analysis of included studies by omitting each study.

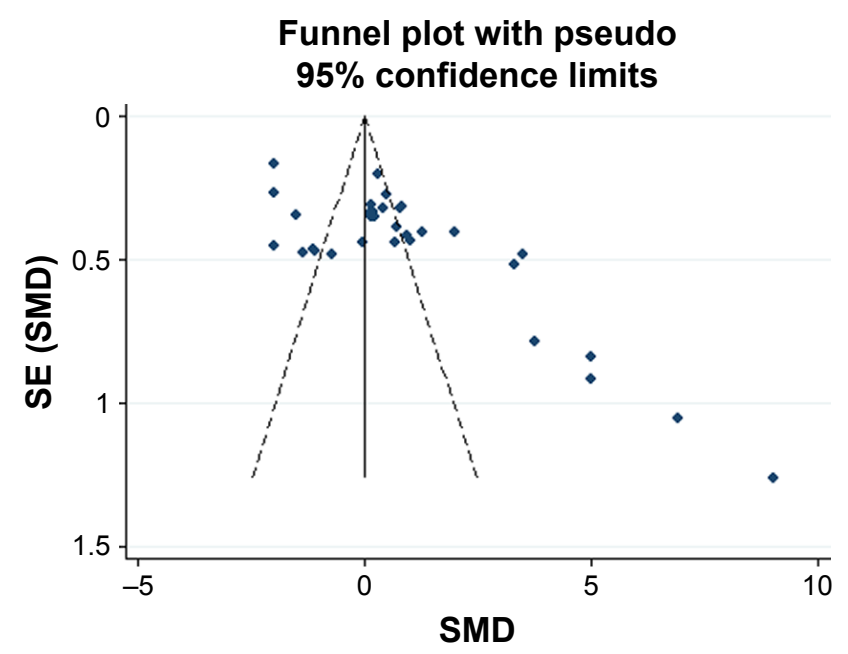

Figure S2 Funnel plot of exhaled nitric oxide in COPD.

Abbreviations: SE, standard error; SMD, standard mean difference. 


\section{References}

1. Brindicci $\mathrm{C}$, Ito $\mathrm{K}$, Resta $\mathrm{O}$, et al. Exhaled nitric oxide from lung periphery is increased in COPD. Eur Respir J. 2005;26(1):52-59.

2. Clini E, Bianchi L, Vitacca M, et al. Exhaled nitric oxide and exercise in stable COPD patients. Chest. 2000;117(3):702-707.

3. de Laurentiis G, Maniscalco M, Cianciulli F, et al. Exhaled nitric oxide monitoring in COPD using a portable analyzer. Pulm Pharmacol Ther. 2008;21(4):689-693.

4. Delen FM, Sippel JM, Osborne ML, et al. Increased exhaled nitric oxide in chronic bronchitis: comparison with asthma and COPD. Chest 2000;117(3):695-701.

5. Hirano T, Matsunaga $\mathrm{K}$, Sugiura $\mathrm{H}$, et al. Relationship between alveolar nitric oxide concentration in exhaled air and small airway function in COPD. J Breath Res. 2013;7(4):046002.

6. Hogman M, Holmkvist T, Wegener T, et al. Extended NO analysis applied to patients with COPD, allergic asthma and allergic rhinitis. Respir Med. 2002;96(1):24-30.

7. Kanazawa H, Shoji S, Yoshikawa T, et al. Increased production of endogenous nitric oxide in patients with bronchial asthma and chronic obstructive pulmonary disease. Clin Exp Allergy. 1998;28(10):1244-1250.

8. Liu J, Sandrini A, Thurston MC, et al. Nitric oxide and exhaled breath nitrite/nitrates in chronic obstructive pulmonary disease patients. Respiration. 2007;74(6):617-623.

9. Maricic L, Vceva A, Visevic R, et al. Assessment of endothelial dysfunction by measuring von Willebrand factor and exhaled nitric oxide in patients with chronic obstructive pulmonary disease. Coll Antropol. 2013;37(4):1153-1160.

10. Montuschi P, Kharitonov SA, Barnes PJ. Exhaled carbon monoxide and nitric oxide in COPD. Chest. 2001;120(2):496-501.

11. Papi A, Romagnoli M, Baraldo S, et al. Partial reversibility of airflow limitation and increased exhaled NO and sputum eosinophilia in chronic obstructive pulmonary disease. Am J Respir Crit Care Med. 2000;162(5):1773-1777.

12. Rawy AM, Mansour AI. Fraction of exhaled nitric oxide measurement as a biomarker in asthma and COPD compared with local and systemic inflammatory markers. Egypt J Chest Diseases\&Tuberculosis. 2015;64(1):13-20.

13. Rouhos A, Kainu A, Piirila P, et al. Repeatability of exhaled nitric oxide measurements in patients with COPD. Clin Physiol Funct Imaging. 2011;31(1):26-31.
14. Rutgers SR, Meijer RJ, Kerstjens HA, et al. Nitric oxide measured with single-breath and tidal-breathing methods in asthma and COPD. Eur Respir J. 1998;12(4):816-819.

15. Shrestha SK, Shrestha S, Sharma L, et al. Comparison of fractional exhaled nitric oxide levels in chronic obstructive pulmonary disease, bronchial asthma and healthy subjects of Nepal. $J$ Breath Res. 2017;11(4):047101.

16. Sun Y, Wang XM, Chen YH, et al. Exhaled hydrogen sulfide in patients with chronic obstructive pulmonary disease and its correlation with exhaled nitric oxide. Chin Med J (Engl). 2013;126(17):3240-3244.

17. Ziora D, Dworniczak S, Kaczmarczyk G, et al. Correlation of exhaled nitric oxide with nitrogen oxides and selected cytokines in induced sputum of chronic obstructive pulmonary disease patients. J Physiol Pharmacol. 2007;58 Suppl 5(Pt 2):791-799.

18. Zietkowski Z, Kucharewicz I, Bodzenta-Lukaszyk A. The influence of inhaled corticosteroids on exhaled nitric oxide in stable chronic obstructive pulmonary disease. Resp Med. 2005;99(7):816-824.

19. Corradi M, Majori M, Cacciani GC, et al. Increased exhaled nitric oxide in patients with stable chronic obstructive pulmonary disease. Thorax. 1999;54(7):572-575.

20. Agusti AG, Villaverde JM, Togores B, et al. Serial measurements of exhaled nitric oxide during exacerbations of chronic obstructive pulmonary disease. Eur Respir J. 1999;14(3):523-528.

21. Santini G, Mores N, Shohreh R, et al. Exhaled and non-exhaled non-invasive markers for assessment of respiratory inflammation in patients with stable COPD and healthy smokers. $J$ Breath Res. 2016;10(1):017102.

22. Beg MF, Alzoghaibi MA, Abba AA, et al. Exhaled nitric oxide in stable chronic obstructive pulmonary disease. Ann of Thorac Med. 2009;4(2):65-70.

23. Moussa SB, Sfaxi I, Tabka Z, et al. Oxidative stress and lung function profiles of male smokers free from COPD compared to those with COPD: a case-control study. Libyan J Med. 2014;9:23873-23873.

24. An L, Carremans C, Bent KD, et al. Alveolar and bronchial exhaled nitric oxide in chronic obstructive pulmonary disease. Resp Med. 2010;104(7):1020-1026.
International Journal of COPD

\section{Publish your work in this journal}

The International Journal of COPD is an international, peer-reviewed journal of therapeutics and pharmacology focusing on concise rapid reporting of clinical studies and reviews in COPD. Special focus is given to the pathophysiological processes underlying the disease, intervention programs, patient focused education, and self management protocols.

\section{Dovepress}

This journal is indexed on PubMed Central, MedLine and CAS. The manuscript management system is completely online and includes a very quick and fair peer-review system, which is all easy to use. Visit http://www.dovepress.com/testimonials.php to read real quotes from published authors. 